\title{
Functional Metathesis Catalyst Through Ring Closing Enyne Metathesis: One Pot Protocol for Living Heterotelechelic Polymers
}

\author{
Subhajit Pal, Fiorella Lucarini, Albert Ruggi, and Andreas F. M. Kilbinger*(-) \\ Department of Chemistry, University of Fribourg, Chemin du Musée 9, CH-1700 Fribourg, Switzerland
}

\begin{abstract}
Enyne ring closing metathesis has been used to synthesize functional group carrying metathesis catalysts from a commercial (Ru-benzylidene) Grubbs' catalysts. The new Grubbs-type ruthenium carbene was used to synthesize living heterotelechelic ROMP polymers without any intermediate purification. Olefin metathesis with a mono substituted alkyne followed by ring closing metathesis with an allylic ether provided efficient access to new functional group carrying metathesis catalysts. Different functional benzylidene and alkylidene derivatives have been investigated in the synthesis of heterotelechelic polymers in one pot.
\end{abstract}

$\mathrm{T}$ oday, ruthenium- and molybdenum-based metathesis catalysts $^{1-3}$ are extensively used to construct carboncarbon double bonds. ${ }^{4}$ The high functional group tolerance of the ruthenium-based catalysts make them not only a popular choice in organic chemistry for ring-closing and crossmetathesis reactions but also in polymer chemistry for the polymerization of functional monomers. ${ }^{5,6}$ The first and third generation Grubbs' catalysts are the most common choice for polymer chemists due to their high initiation to propagation rate ratio (Figure 1, G1 and G3), which allows their use in living polymerizations. ${ }^{7}$

In addition to main-chain functionality, polymers in which the chain ends can be addressed with high specificity are of great importance in a number of disciplines bordering chemistry, such as materials science, biochemistry or medicine. $^{8-11}$

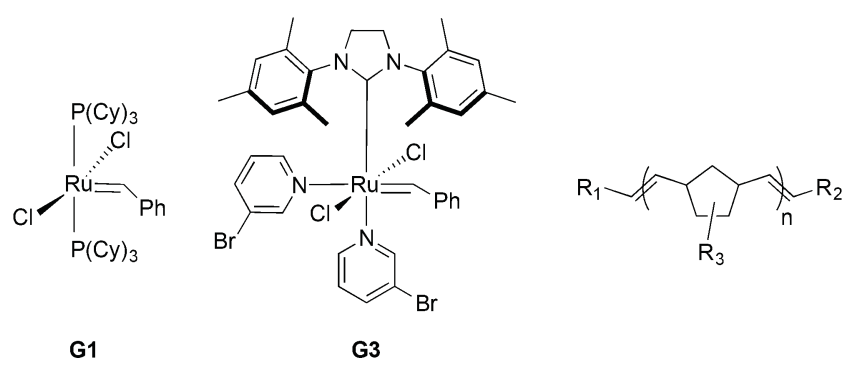

Figure 1. Left and center: first generation (G1) and third generation (G3) Grubbs' catalyst. Right: An end-functional polymer (here a polynorbornene derivative) is called homotelechelic (for $R_{1}=R_{2}$ ) or heterotelechelic (for $R_{1} \neq R_{2}$ ) assuming both groups $R_{1}$ and $R_{2}$ can undergo postpolymerization reactions.
Mono end-functional polymers can be made by functionally terminating living ring opening metathesis polymerizations. Many methods have been described to prepare polymers with alcohol, thiol, carboxylic acid, aldehyde or amine end groups in addition to the introduction of entire groups and moieties. ${ }^{12-20}$

Sacrificing the living character of the polymerization allows the synthesis of homotelechelic polymers (Figure 1), typically from monomers such as cyclooctene or cyclooctadiene. ${ }^{21-24}$ Exploiting the propagation and cross-metathesis kinetics of the Grubbs' third generation complex, homotelechelics can also be prepared in a living manner. ${ }^{25,26}$

Heterotelechelic polymers (Figure 1) are, by nature, more difficult to synthesize. The sacrificial block copolymer method was used to prepare polymers carrying alcohol and either aldehyde or carboxylic acid end groups. ${ }^{27}$ In one case, a regioselective chain transfer agent was exploited to prepare heterotelechelic polymers. ${ }^{28}$ Functional polymer initiation followed by functional termination will allow the synthesis of heterotelechelic polymers. Functional initiators can be prepared by cross-metathesis reactions using functional acyclic olefins. ${ }^{29-33}$ However, the olefin is typically used in excess and the newly prepared initiator needs to be purified prior to polymerization.

Prefunctionalization agents (PFAs) can be used in excess to prefunctionalize the ruthenium carbene complex without the need for purification as the excess is rendered metathesis inactive (or less active than the monomer that is introduced afterward). Previously reported PFAs worked particularly well with G1 but were limited to functional group bearing benzylidene complexes. ${ }^{34}$

Here, we report a new PFA that can be used with G1 and G3 yielding functional group carrying benzylidene and alkylidene complexes.

The reactivity of alkynes toward olefin metathesis has been described $^{35-38}$ and enyne metathesis has been used in organic chemistry for many years. ${ }^{39}$ Recently, the Choi group reported a tandem ring-opening ring-closing cross metathesis polymerization using an enyne sequence. ${ }^{40-42}$ We hypothesized that the reactivity of a monosubstituted alkyne toward olefin metathesis would be higher than that of di or tri substituted allylic ethers. As a consequence, G1 or G3 would react faster with a terminal alkyne than an allylic olefin. The newly formed carbene (Scheme 1, A) would ideally undergo an intramolecular ring closing reaction (Scheme $1, k_{\mathrm{RCM}}$ ) rather than an intermolecular propagation reaction with another alkyne. 

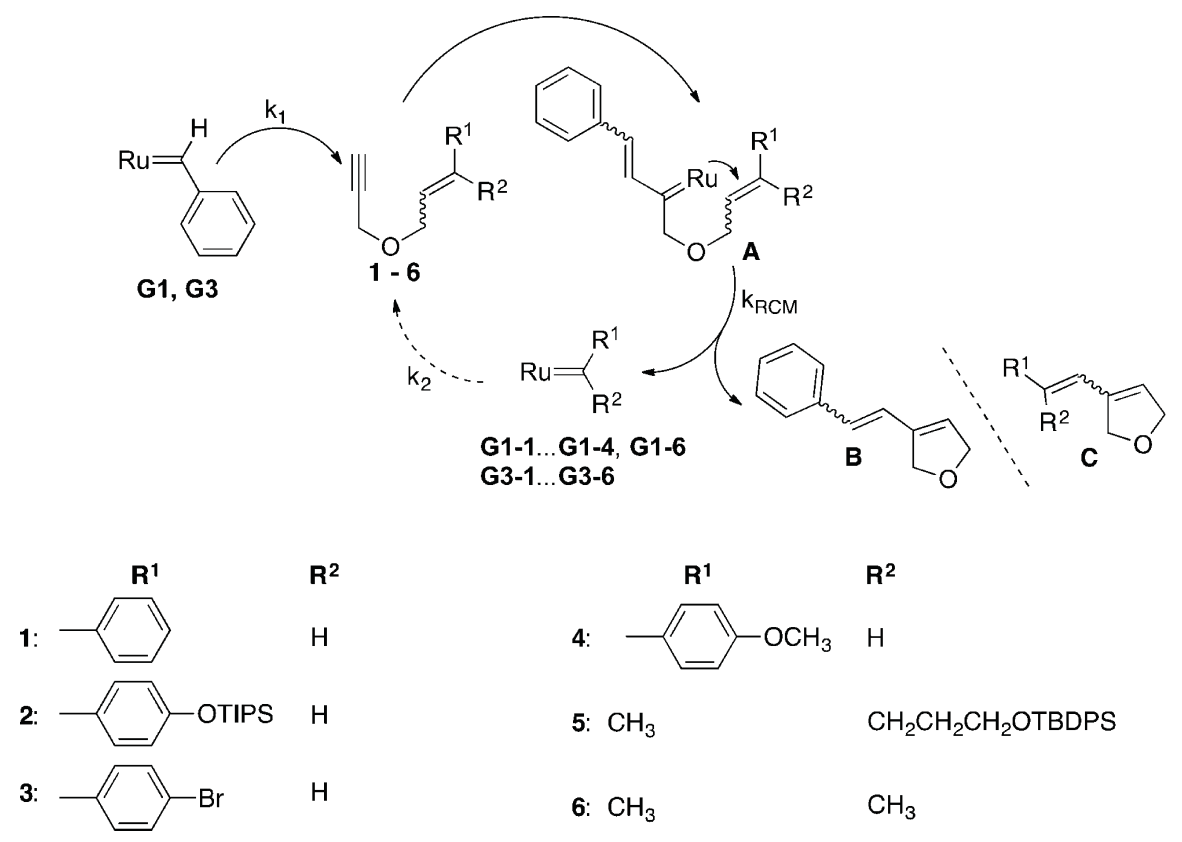

${ }^{a}$ For G1, the reaction was carried out at $\mathrm{rt}$. For G3, the reaction was carried out at $-10^{\circ} \mathrm{C}$ or at $\mathrm{rt}$ in the presence of 3-bromopyridine (30 equiv).

This cyclization yields the new functionalized ruthenium carbene (Scheme 1, $\mathrm{Ru}=\mathrm{CR}_{1} \mathrm{R}_{2}$ ) and a 2,5-dihydrofuran derivative (DHF, Scheme 1, B). As PFA 1-6 would be used in excess, the newly formed ruthenium carbene would undergo further enyne metathesis with excess 1-6 (Scheme $1, k_{2}$ ), thereby producing a new DHF derivative (Scheme 1, C) and regenerating itself in the process. At the end of the cycle, the reaction mixture would only contain the two DHF derivatives (Scheme 1, B and C) and a functionalized ruthenium carbene. The DHF derivatives should ideally show lower metathesis reactivity due to a lack of ring strain and, therefore, a subsequent polymerization could be carried out by simply adding a strained monomer to the same reaction vessel without any purification or workup.

To verify our hypothesis, compounds $1-6$ were synthesized (Scheme 1). As an initial test, 1 was subjected to $10 \mathrm{~mol} \%$ of G1 in dichloromethane- $d_{2}$ and the expected formation of 3styryl-2,5-dihydrofuran (Scheme 1, B) could be observed immediately (see Supporting Information (SI) for characterization of $E$ and $Z$ isomers).

The prefunctionalization of G1 using 3 equiv of either $\mathbf{2 - 4}$ was followed by ${ }^{1} \mathrm{H}$ NMR spectroscopy in dichloromethane- $d_{2}$. The disappearance of the benzylidene carbene signal (20.03 ppm) and the formation of the respective new carbene signals in excellent yields could be observed (Figure 2 and SI Figure S1). As a proof of principle that the synthesis of heterotelechelic polymers in one pot can be achieved following this route, exo- $N$-methyl norbornene imide (MNI, 17 equiv, 3 h) was added to the prefunctionalized ruthenium carbene complexes G1-2 and G1-3 without any intermediate purification (Scheme 2). The G1-2 initiated poly(MNI) was terminated with chain transfer agent (CTA) 10 (20 equiv, $1 \mathrm{~h}$, see Scheme 2), yielding a heterotelechelic polymer with a TIPS protected phenolic alcohol on one chain end and an aldehyde on the other $\left(\mathrm{Mn}_{\mathrm{GPC}}=5100 \mathrm{~g} \mathrm{~mol}^{-1}, Ð=1.2\right.$, poly i, see $\left.\mathrm{SI}\right)$. The G1-3 initiated poly(MNI) was terminated with CTA 9 resulting in a heterotelechelic polymer with an aryl bromide on one chain end and a BOC protected allylic amine on the other $\left(\mathrm{Mn}_{\mathrm{GPC}}=6300 \mathrm{~g} \mathrm{~mol}^{-1}, Ð=1.2\right.$, poly $\mathrm{h}$, see SI $)$.

The synthesis of ruthenium alkylidene initiators is of interest because of their faster rate of initiation compared to ruthenium benzylidenes. Reports for one pot syntheses of alkylidene initiators without the need for purification or workup are rare. $^{25,26}$

We therefore reacted 3 equiv of $\mathbf{6}$ with $\mathbf{G} \mathbf{1}$ in dichloromethane- $d_{2}$. Unfortunately, only $36 \%$ of the benzylidene signal (20.03 ppm) disappeared over $3 \mathrm{~h}$ indicating that the ${ }^{1} \mathrm{H}$ NMR silent ruthenium iso-propylidene complex could not have formed in high yield. We postulate that the newly formed ruthenium iso-propylidene is faster at reacting with propargyl ether 6 (Scheme 1, $k_{2}$ ) than the G1-benzylidene (Scheme 1, $k_{1}$ ) resulting in incomplete conversion of the G1-benzylidene. To achieve higher conversions, the amount of $\mathbf{6}$ was increased (10 equiv). Unfortunately, only $64 \%$ conversion of G1-benzylidene into the iso-propylidene complex could be observed. (see SI). Similar observations had previously been made with a norbornene-based PFA and G1. ${ }^{34}$

Next, we investigated the prefunctionalization of G3 (Figure 1) with PFA 1-6 (Scheme 1). Carrying out the reaction at rt in dichloromethane- $d_{2}$, we observed rapid catalyst decomposition by ${ }^{1} \mathrm{H}$ NMR spectroscopy. Model experiments indicated that the $\mathbf{G} 3$ benzylidene complex decomposes in the presence of 3styryl-2,5-dihydrofuran as evidenced by new carbene species formed in the region of $18-19 \mathrm{ppm}$ (Scheme $1 \mathrm{~B}$ and SI Figure S3). The mechanism of this decomposition is under investigation.

To avoid this decomposition, a RCEYM of G3 with $\mathbf{3}$ was carried out at $-10{ }^{\circ} \mathrm{C}$ in dichloromethane- $d_{2}$ (Scheme 1 ). The reaction was followed by ${ }^{1} \mathrm{H}$ NMR spectroscopy. Within 45 min, the original G3 benzylidene signal (19.06 ppm) shifted to a new carbene signal (19.05 ppm) with little loss of signal intensity (87\%, Figure 2d). The reaction of $\mathbf{2}$ and $\mathbf{4}$ with G3 under identical conditions (Scheme 1) yielded new carbenes in high yields ( $90 \%$ for $2,96 \%$ for 4 , see SI). 

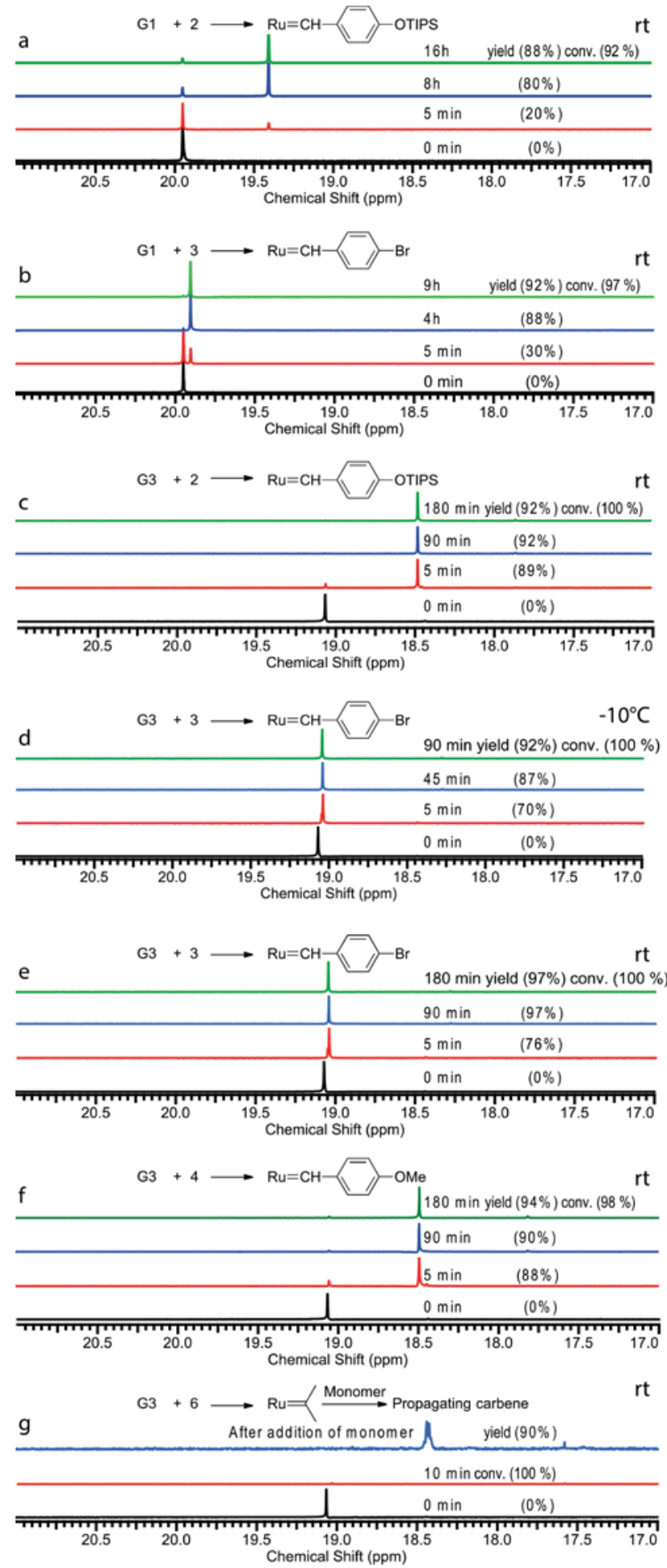

Figure 2. ${ }^{1} \mathrm{H}$ NMR spectra $\left(\mathrm{CD}_{2} \mathrm{Cl}_{2}, 400 \mathrm{MHz}\right)$ of reactions: (a) G1 with 2 forming G1-OTIPS (19.49 ppm), (b) G1 with 3 forming G1Br (19.99 ppm), (c) G3 with 2 forming G1-OTIPS (18.55 ppm) at rt in the presence of 30 equiv of 3-bromopyridine, (d) G3 with 3 forming G3-Br (19.05 ppm) at $-10{ }^{\circ} \mathrm{C}$, (e) $\mathbf{G} 3$ with $\mathbf{3}$ forming G3-Br $(19.05 \mathrm{ppm})$ at $\mathrm{rt}$ in the presence of 30 equiv of 3-bromopyridine, ( $\mathrm{f}$ ) G3 with $\mathbf{4}$ forming G3-OMe (18.57 ppm) at rt in the presence of 30 equiv of 3-bromopyridine and g) reaction of G3 with $\mathbf{6}$ forming G3isopropylidene followed by addition of MNI gives the propagating carbene $(18.50 \mathrm{ppm})$ at $\mathrm{rt}$ in the presence of 30 equiv of 3bromopyridine. $($ conv. $=$ conversion $)$.
Scheme 2. One Pot Synthesis of Heterotelechelic Polymers

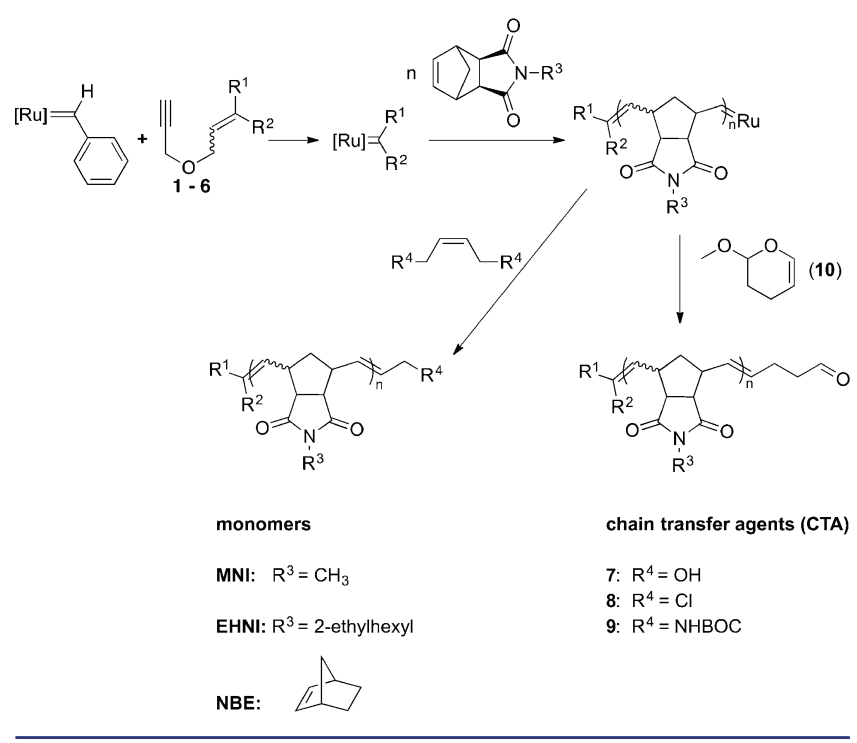

The RCEYM of $\mathbf{G} 3$ either with $\mathbf{5}$ or $\mathbf{6}$ was investigated by ${ }^{1} \mathrm{H}$ NMR spectroscopy in dichloromethane- $d_{2}$ at $-10{ }^{\circ} \mathrm{C}$ (see SI Table 1). Unlike in the case of G1 (see above), the G3 benzylidene signal quantitatively shifted to an alkylidene carbene (complete disappearance of the benzylidene signal for 5 and $\mathbf{6}$ ) using only 5 equiv of the corresponding PFAs 5 or 6 at $-10{ }^{\circ} \mathrm{C}$. We assume that the rate of reaction between G3 benzylidene and $\mathbf{5}$ or $\mathbf{6}$ (Scheme 1, $k_{1}$ ) is higher than the rate of ring closing metathesis (Scheme $1, k_{\mathrm{RCM}}$ ), leading to a fast consumption of the $\mathbf{G} 3$ benzylidene complex. The newly formed carbenes G3-5 or G3-6 are, therefore, no longer in competition with the original G3 benzylidene for the PFA substrates.

To lower its reactivity, we carried out the RCEYM of G3 with 3 in the presence of 30 equiv of 3-bromopyridine in dichloromethane- $d_{2}$ at $\mathrm{rt} .{ }^{1} \mathrm{H}$ NMR spectroscopy revealed that the G3 benzylidene signal shifted completely to the new benzylidene signal without appreciable loss of catalyst (19.05 ppm, 97\%, Figure 2e). The remaining substrates were subjected to $\mathbf{G 3}$ at identical reaction conditions and generated the corresponding new carbene complexes in high yields (see Figure 2). The minimum excess of PFA was investigated for the reaction between G3 and 4. 1.5 equiv of $4(0.06 \mathrm{M})$ were sufficient to give $91 \%$ conversion into the new carbene species in the presence of 30 equiv of 3-bromopyridine (see SI).

Heterotelechelic polymers were synthesized using both methods, i.e., low temperature prefunctionalization and 3bromopyridine attenuation. G3 was prefunctionalized with $\mathbf{4}$ at $-10{ }^{\circ} \mathrm{C}(120 \mathrm{~min})$ followed by polymerization of MNI (30 equiv, $3 \mathrm{~h}$ ) and functional termination with 7 (20 equiv, $1 \mathrm{~h}$ ) giving a methoxyphenyl initiated polymer with an allylic alcohol end group $\left(\mathrm{Mn}_{\mathrm{GPC}}=6100 \mathrm{~g} \mathrm{~mol}^{-1}, Ð=1.07\right.$, poly a, see SI $)$. Similarly, heterotelechelic poly(MNI)s were prepared at -10 ${ }^{\circ} \mathrm{C}$ via prefunctionalization with 3 and termination with 7 $\left(\mathrm{Mn}_{\mathrm{GPC}}=4500 \mathrm{~g} \mathrm{~mol}^{-1}, Ð=1.06\right.$, poly $\mathbf{b}$, see $\left.\mathrm{SI}\right)$, prefunctionalization with 2 and termination with $10\left(\mathrm{Mn}_{\mathrm{GPC}}\right.$ $=5200 \mathrm{~g} \mathrm{~mol}^{-1}, Ð=1.06$, poly c, see SI) and prefunctionalization with 5 and termination with $10\left(\mathrm{Mn}_{\mathrm{GPC}}\right.$ $=7300 \mathrm{~g} \mathrm{~mol}^{-1}, Ð=1.06$, poly e, see SI). Using norbornene as monomer at $-10{ }^{\circ} \mathrm{C}$ prefunctionalization with 3 and termination with $7\left(\mathrm{Mn}_{\mathrm{GPC}}=3900 \mathrm{~g} \mathrm{~mol}^{-1}, Ð=1.24\right.$, poly 
g, see SI) gave a poly(NBE) with an aryl bromide at one chain end and an allylic alcohol on the other.

Carrying out the polymerization of MNI at $\mathrm{rt}$ in the presence of 30 equiv of 3-bromopyridine: prefunctionalization with 6 (10 min), polymerization of MNI (60 equiv, $3 \mathrm{~h}$ ) and termination with 7 gave poly $\mathbf{d}\left(\mathrm{Mn}_{\mathrm{GPC}}=11300 \mathrm{~g} \mathrm{~mol}^{-1}, Ð=1.06\right)$, prefunctionalization with 3 and termination with 8 gave poly $j$ $\left(\mathrm{Mn}_{\mathrm{GPC}}=11300 \mathrm{~g} \mathrm{~mol}^{-1}, Ð=1.06\right)$ and prefunctionalization with $\mathbf{5}$ and termination with 9 gave poly $\mathbf{k}\left(\mathrm{Mn}_{\mathrm{GPC}}=11300 \mathrm{~g}\right.$ $\left.\mathrm{mol}^{-1}, Ð=1.06\right)$. Using exo- $N$-(2-ethylhexyl)norbornene imide as monomer, prefunctionalization with 3 and termination with 7 gave heterotelechelic poly $(\mathrm{EHNI})$ (poly f, $\mathrm{Mn}_{\mathrm{GPC}}=5300 \mathrm{~g}$ $\mathrm{mol}^{-1}, Ð=1.06$, see also SI for all polymers).

GPC analysis showed narrow molecular weight distributions and MALDI-ToF mass spectrometry confirmed the presence of both functional end groups in all cases (see SI). A detailed ${ }^{1} \mathrm{H}$ NMR end group analysis was carried out for poly $\mathbf{j}$ (see SI).

To prove the presence of two different end functional groups, a polymer was prepared carrying a Coumarin 343 and Rhodamine B dye on opposite chain ends (see SI). Förster resonance energy transfer (FRET) from the excited Coumarin dye to the Rhodamine fluorophore proved the presence of both chromophores in close proximity (see SI).

In conclusion, we have successfully developed new PFAs for both G1 and G3. Methoxy, bromo, triisopropylsiloxy and substituted alkylidene catalysts were synthesized in excellent yields. Heterotelechelic polymers were prepared using these PFAs, G1 and G3 in one pot reactions without intermediate purification. End-functionalization was achieved using symmetrical olefin chain transfer agents to install allylic hydroxy, chloro or amine end groups or 2-methoxy-3,4-dihydro-2Hpyran to install aldehyde end groups. ${ }^{1} \mathrm{H}$ NMR, FRET and GPC analyses show an excellent degree of end functionalization and good control over molecular weight confirming the living character of the polymerizations. This method provides an easy and efficient approach to functional Grubbs' metathesis catalysts using PFAs that can be prepared in few straightforward steps. The heterotelechelic polymers that are accessible via this route can serve as building blocks for preparing a wide range of new materials from functional bioconjugates and well-defined copolymer architectures to reactive surface coatings.

\section{ASSOCIATED CONTENT}

\section{S Supporting Information}

The Supporting Information is available free of charge on the ACS Publications website at DOI: 10.1021/jacs.7b12805.

Full experimental details, NMR spectra, MALDI ToF MS and GPC data, description of the FRET experiments (PDF)

\section{AUTHOR INFORMATION}

\section{Corresponding Author}

*andreas.kilbinger@unifr.ch

\section{ORCID $\odot$}

Andreas F. M. Kilbinger: 0000-0002-2929-7499

\section{Notes}

The authors declare no competing financial interest.

\section{ACKNOWLEDGMENTS}

The authors thank the National Center of Competence in Research (NCCR Bioinspired Materials, Swiss National Science Foundation) for support.

\section{REFERENCES}

(1) Calderon, N.; Ofstead, E. A.; Judy, W. A. Angew. Chem., Int. Ed. Engl. 1976, 15, 401.

(2) Ivin, K. J.; Mol, J. C. Olefin metathesis and metathesis polymerization; Academic Press: New York, 1997.

(3) Kress, S.; Blechert, S. Chem. Soc. Rev. 2012, 41, 4389.

(4) Calderon, N. Acc. Chem. Res. 1972, 5, 127-132.

(5) Grubbs, R. H. Handbook of Metathesis; Wiley-VCH: Weinheim, 2003.

(6) Bielawski, C. W.; Grubbs, R. H. Prog. Polym. Sci. 2007, 32, 1.

(7) Schwab, P.; France, M. B.; Ziller, J. W.; Grubbs, R. H. Angew. Chem., Int. Ed. Engl. 1995, 34, 2039.

(8) Maynard, H. D.; Okada, S. Y.; Grubbs, R. H. Macromolecules 2000, 33, 6239.

(9) Maynard, H. D.; Okada, S. Y.; Grubbs, R. H. J. Am. Chem. Soc. 2001, 123, 1275 .

(10) Lynn, D. M.; Mohr, B.; Grubbs, R. H.; Henling, L. M.; Day, M. W. J. Am. Chem. Soc. 2000, 122, 6601.

(11) Stubbs, L. P.; Weck, M. Chem. - Eur. J. 2003, 9, 992.

(12) Katayama, H.; Fukuse, Y.; Nobuto, Y.; Akamatsu, K.; Ozawa, F. Macromolecules 2003, 36, 7020.

(13) Kolonko, E. M.; Kiessling, L. L. J. Am. Chem. Soc. 2008, 130, 5626.

(14) Owen, R. M.; Gestwicki, J. E.; Young, T.; Kiessling, L. L. Org. Lett. 2002, 4, 2293.

(15) Rybak, A.; Fokou, P. A.; Meier, M. A. R. Eur. J. Lipid Sci. Technol. 2008, 110, 797 .

(16) Lexer, C.; Saf, R.; Slugovc, C. J. Polym. Sci., Part A: Polym. Chem. 2009, 47, 299.

(17) Liu, P.; Yasir, M.; Kurzen, H.; Hanik, N.; Schäfer, M.; Kilbinger, A. F. M. J. Polym. Sci., Part A: Polym. Chem. 2017, 55, 2983.

(18) Nagarkar, A.; Crochet, A.; Fromm, K.; Kilbinger, A. F. M. Macromolecules 2012, 45, 4447.

(19) Hilf, S.; Kilbinger, A. F. M. Nat. Chem. 2009, 1, 537.

(20) Matson, J.; Grubbs, R. H. Macromolecules 2010, 43, 213.

(21) Bielawski, C. W.; Benitez, D.; Morita, T.; Grubbs, R. H. Macromolecules 2001, 34, 8610.

(22) Hillmyer, M. A.; Grubbs, R. H. Macromolecules 1993, 26, 872.

(23) Hillmyer, M. A.; Grubbs, R. H. Macromolecules 1995, 28, 8662.

(24) Hillmyer, M. A.; Nguyen, S. T.; Grubbs, R. H. Macromolecules 1997, 30, 718 .

(25) Hanik, N.; Kilbinger, A. F. M. J. Polym. Sci., Part A: Polym. Chem. 2013, 51, 4183.

(26) Matson, J. B.; Virgil, S. C.; Grubbs, R. H. J. Am. Chem. Soc. 2009, $131,3355$.

(27) Hilf, S.; Kilbinger, A. F. M. Macromolecules 2010, 43, 208.

(28) Radlauer, M. R.; Matta, M. E.; Hillmyer, M. A. Polym. Chem. 2016, 7, 6269.

(29) Burtscher, D.; Saf, R.; Slugovc, C. J. Polym. Sci., Part A: Polym. Chem. 2006, 44, 6136.

(30) Katayama, H.; Urushima, H.; Ozawa, F. J. Organomet. Chem. 2000, 606, 16.

(31) Bielawski, C. W.; Louie, J.; Grubbs, R. H. J. Am. Chem. Soc. 2000, 122, 12872.

(32) Ambade, A. V.; Yang, S. K.; Weck, M. Angew. Chem., Int. Ed. 2009, 48, 2894.

(33) Ambade, A. V.; Yang, S. K.; Weck, M. Angew. Chem. 2009, 121, 2938.

(34) Nagarkar, A.; Yasir, M.; Crochet, A.; Fromm, K. M.; Kilbinger, A. F. M. Angew. Chem., Int. Ed. 2016, 55, 12343.

(35) Katsumata, T.; Shiotsuki, M.; Kuroki, S.; Ando, I.; Masuda, T. Polym. J. 2005, 37, 608. 
(36) Katsumata, T.; Shiotsuki, M.; Masuda, T. Macromol. Chem. Phys. 2006, 207, 1244.

(37) Csabai, P.; Joo, F.; Trzeciak, A. M.; Ziołkowski, J. J. J. Organomet. Chem. 2006, 691, 3371.

(38) Katsumata, T.; Shiotsuki, M.; Sanda, F.; Sauvage, X.; Delaude, L.; Masuda, T. Macromol. Chem. Phys. 2009, 210, 1891.

(39) Diver, S. T.; Giessert, A. J. Chem. Rev. 2004, 104, 1317.

(40) Park, H.; Choi, T. L. J. Am. Chem. Soc. 2012, 134, 7270.

(41) Park, H.; Lee, H. K.; Choi, T. L. J. Am. Chem. Soc. 2013, 135, 10769.

(42) Park, H.; Kang, E. H.; Muller, L.; Choi, T. L. J. Am. Chem. Soc. 2016, 138, 2244 